\title{
CITOTOXICIDADE DOS EXTRATOS GLICÓLICOS DE Cynara scolymus (ALCACHOFRA), Myracrodruom urundeuva (AROEIRA-DO-SERTÃO) E Camellia sinensis (CHÁ VERDE)
}

\section{CYTOTOXICITY OF Cynara scolymus (ARTICHOKE), Myracrodruom urundeuva (AROEIRA-DO-SERTÃO) AND Camellia sinensis (GREEN TEA) GLYCOLIC EXTRACTS}

\author{
Karen Cristiane Higa ${ }^{1}$ \\ Adeline Lacerda Jorjão ${ }^{2}$ \\ Felipe Eduardo Oliveira ${ }^{3}$ \\ Jonatas Rafael de Oliveira ${ }^{4}$ \\ Graziella Nuernberg Back Brito ${ }^{5}$ \\ Antonio Olavo Cardoso Jorge ${ }^{6}$ \\ Luciane Dias de Oliveira ${ }^{7}$
}

Resumo: Produtos naturais, como extratos glicólicos de plantas, são importantes para a aplicação clínica na área da saúde, como em enxaguatórios bucais, cremes dentais e irrigação intracanal. Assim é necessário realizar estudos de citotoxicidade desses extratos glicólicos. O presente estudo buscou avaliar a atividade citotóxica dos extratos glicólicos de Cynara scolymus L. (alcachofra), Myracrodruom urundeuva Allem. (aroeira-do-sertão-do-sertão) e Camellia sinensis (L.) Kuntze (chá verde) em macrófagos de camundongo (RAW 264.7) pelo teste de atividade metabólica MTT. Para tanto, as células foram distribuídas em microplacas de 96 poços e foram expostas a 11 diluições seriadas de cada extrato (200 mg/mL, $100 \mathrm{mg} / \mathrm{mL}, 50 \mathrm{mg} / \mathrm{mL}, 25 \mathrm{mg} / \mathrm{mL}, 12,5 \mathrm{mg} / \mathrm{mL}, 6,25 \mathrm{mg} / \mathrm{mL}, 3,13 \mathrm{mg} / \mathrm{mL}, 1,56 \mathrm{mg} / \mathrm{mL}, 0,78$ $\mathrm{mg} / \mathrm{mL}, 0,39 \mathrm{mg} / \mathrm{mL}$ e $0,20 \mathrm{mg} / \mathrm{mL}$ ), sendo $n=8$ para cada diluição. Após o tempo de contato de 5 minutos e 24 horas, foi avaliada a viabilidade celular utilizando o teste MTT. Diante destes resultados, no tempo de exposição de 5 minutos com os extratos, em ordem crescente de redução da viabilidade celular, seguiram-se o chá verde, com aumento da viabilidade celular, a aroeira-do-sertão e o extrato de alcachofra. Por meio do MTT dos três extratos por tempo de exposição de 24 horas, observou-se que $o$ extrato de alcachofra apresentou maior toxicidade, seguido do extrato de chá verde e aroeira-do-sertão. $A$ análise estatística foi realizada por ANOVA e teste de Tukey, com significância de 5\%. Conclusões: Entre os extratos, o chá verde com 12,5mg/mL, com interessantes 5 minutos e 24 horas, despertou atenção, pois foi a maior concentração e não apresentou citotoxicidade para os macrófagos, assim como a alcachofra que foi a mais citotóxica para os macrófagos, em ambos os tempos (5 min e 24 h).

Palavras-chave: Chá verde; alcachofra; aroeira-do-sertão; atividade citotóxica; macrófagos.

Abstract: Natural products such as glycolic extracts of plants are important for the clinical application in

\footnotetext{
1 Doutora em Biopatologia Bucal. Docente da Universidade Anhanguera de São Paulo, Brasil. E-mail: higa_ka@hotmail.com.

2 Doutora em Biopatologia Bucal. Docente da Universidade Anhanguera de São Paulo, Brasil. E-mail: adelinejorjao@gmail.com.

3 Docente do Centro Universitário Brascubas, Brasil. E-mail: felipe.eoliveira@ymail.com.

4 Universidade Estadual Paulista Júlio de Mesquita Filho, Brasil. E-mail: jroliveira16@hotmail.com.

5 Doutora em Biopatologia Bucal. Professora da Pós-Graduação Biopatologia Bucal da Universidade Estadual Paulista Júlio de Mesquita Filho, Brasil. E-mail: grazinback@yahoo.com.br.

6 Doutor em Biopatologia Bucal. Professor Titular da Universidade Estadual Paulista Júlio de Mesquita Filho, Brasil. E-mail: olavo.jorge@unesp.br.

7 Doutora em Biopatologia Bucal. Professora Adjunto da Universidade Estadual Paulista Júlio de Mesquita Filho, Brasil. E-mail: luciane@fosjc.unesp.br.
} 
health care, like mouthwashes, toothpastes and intracanal irrigation. It is therefore necessary to perform cytotoxicity studies of these glycolic extracts. Objectives: This study aimed to assess the cytotoxic activity of Cynara scolymus (artichoke), Myracrodruom urundeuva Allem. (aroeira-do-sertão) and Camellia sinensis (L.) Kuntze (green tea) glycolic extracts in mouse macrophages (RAW 264.7) by the MTT metabolic activity test. Design: Macrophages were distributed into 96-well plates and exposed to 11 serial dilutions of each extract $(200 \mathrm{mg} / \mathrm{mL}, 100 \mathrm{mg} / \mathrm{mL}, 50 \mathrm{mg} / \mathrm{mL}, 25 \mathrm{mg} / \mathrm{mL}, 12.5 \mathrm{mg} / \mathrm{mL} 6.25 \mathrm{mg} / \mathrm{mL}, 3.13$ $\mathrm{mg} / \mathrm{mL}, 1.56 \mathrm{mg} / \mathrm{mL}, 0.78 \mathrm{mg} / \mathrm{mL}, 0.39 \mathrm{mg} / \mathrm{mL}$ and $0.20 \mathrm{mg} / \mathrm{mL}$ ), with $n=8$ for each dilution. After $5 \mathrm{~min}$ and 24 h of contact, cell viability was assessed using the MTT assay. Results: Given these results, using 5 min of exposure time to the extracts, in ascending order of cell viability reduction follows green tea, with increased cell viability, pepper tree and artichoke. In the MTT assay of the extracts using exposure time of $24 \mathrm{~h}$, it was observed that artichoke extract showed the greatest toxicity, followed by green tea and pepper tree extracts. Statistical analysis was performed by ANOVA and Tukey's test, with a significance level of 5\%. Conclusions: Among the extracts, green tea with $12.5 \mathrm{mg} / \mathrm{mL}$ had interesting results for 5 min and 24 $h$, since this was the highest concentration and it wasn't cytotoxic to the macrophages, and artichoke was the most cytotoxic to the macrophages in both times (5 min and $24 \mathrm{~h}$ ).

Keywords: Green tea; artichoke; pepper tree; cytotoxic activity; macrophages.

\section{INTRODUÇÂO}

O trabalho foi elaborado a partir do resultado de tese de doutorado da Karen Cristiane Higa no Instituto de Ciência e Tecnologia da UNESP.

A utilização da natureza para fins terapêuticos é tão antiga quanto a civilização humana. Nas florestas tropicais, que correspondem a 7\% da superfície da terra, há concentração de mais da metade das espécies vegetais. Diante de tamanha variedade da flora, há poucas pesquisas que aplicam plantas medicinais à produção de fármacos. A partir da planta até obter o medicamento fitoterápico são necessários testes de citotoxicidade para garantir a segurança e testes que confirmem a efetividade de sua ação in vitro e in vivo.

Assim, as pesquisas aplicadas ao conhecimento tradicional de plantas medicinais aliadas à pesquisa científica e à aplicação de tecnologias modernas potencializarão a produção de novos medicamentos, incluindo substâncias de uso odontológico como dentifrícios e enxaguatórios bucais.

Cynara scolymus L. conhecida popularmente como alcachofra pertence à família Asteraceae e a infusão de suas folhas secas via oral são usadas como antidispéptico, colerético e colagogo. As folhas são de grande utilidade por conter em sua composição até $2 \%$ de ácidos fenólicos (ácido cafeico, ácido clorogênico e cinarina), contém até $4 \%$ de lactonas sesquiterpênicas, em sua maior parte cinaropicrina e por volta de $0,5 \%$ de flavonóides, principalmente glicosídeos da luteolina. A alcachofra é uma planta nativa da região mediterrânea e tem demonstrado resultados promissores para diferentes indicações terapêuticas. Zapolska-Downar et al. (2002) verificaram que os extratos aquosos e etanólicos de C. scolymus possuem propriedades protetoras contra o estresse oxidativo induzido por medidores inflamatórios (TNF- $\alpha$ ) e LPS em células endoteliais e monócitos. Em 2013, Tanaka et al. triaram vários extratos de plantas para verificar seu possível efeito inibitório sobre a atividade do fator de 
transcrição nuclear kappa B (NF-kB), citocinas inflamatórias e metaloproteinase da matriz-1 (MMP-1) e verificaram que o extrato de $C$. scolymus mostrou importante efeito na supressão do fator NF-kB. Contudo, são poucos os estudos com o extrato glicólico de $C$. scolymus, o qual é um candidato potencial para ser analisado por sua ação antiinflamatória, sendo de interesse analisar sua citotoxicidade.

Myracrodruon urundeuva Allemão (aroeira-do-sertão) pertence à família Anacardiaceae, sendo encontrada no Nordeste do Brasil. Em 2015, Saraiva et al. pesquisaram sobre plantas medicinais de Pernambuco e observaram que os extratos de aroeira são obtidos através do preparo das folhas, das raízes, das cascas de galhos e dos troncos. Nas cascas foram isoladas chalconas diméricas: urundeuvina $A$, $B$ e $C$ e matosina. A infusão das cascas pode ser usada por via oral ou para banhos de assento. As indicações terapêuticas são abrangentes como ação anti-inflamatória, expectorante, para tratamento de gonorreia, úlceras bucais, doenças nas gengivas e tratamento de influenza.

Em 2015, Carvalho et al. realizaram um estudo etnofarmacológico de plantas comercializadas para fins terapêuticos em mercados públicos no Nordeste do Brasil. Entre as 91 espécies pesquisadas, a aroeira-do-sertão ficou entre as 8 espécies mais versáteis quanto ao seu uso. O cozimento das suas cascas pode ser usado para tratamento de feridas na pele, inflamação, dor, comichão, cistite, uretrite, diarreia e cólicas abdominais.

Em 2013, Carlini, Duarte-Almeida e Tabach realizaram uma avaliação da toxicidade da aroeira-do-sertão em ratos machos com tratamento crônico por 83 dias com duas dosagens via oral de 17,6 e $13,8 \mathrm{mg} / \mathrm{kg}$ e não houve alterações anatomopatológicas, no número de hemácias e na fertilidade.

A Schinus terebinthifolius, conhecida como aroeira-da-praia pertencente a mesma família da aroeira-do-sertão foi pesquisada por Freires et al. (2013). A pesquisa foi baseada em um ensaio clínico randomizado comparando dois tipos de enxaguatórios no tratamento de gengivite e no acúmulo de biofilme durante 10 dias consecutivos em crianças. Um dos enxaguatórios continha $0,3 \%$ de tintura das cascas do caule da aroeira-da-praia e no outro havia clorexidina $0,12 \%$. Os resultados demonstraram que a tintura da aroeira-da-praia apresentou propriedade antiinflamatória semelhante a clorexidina $0,12 \%$, entretanto, não reduziu o biofilme como esta. Diante desses estudos, pode-se verificar que a aroeira-do-sertão apresenta interesse terapêutico, inclusive odontológico, porém, as pesquisas ainda são escassas e pouco conclusivas.

Outro possível candidato a apresentar ação anti-inflamatória é o extrato glicólico de chá verde. Como bebida, o chá verde é cada vez mais consumido. Esta droga vegetal provêm das folhas não fermentadas da Camellia sinensis (L.) Kuntze. Esta espécie pertence a família Theaceae, habita climas úmidos e frescos e é muito encontrada na Ásia e no sul do Brasil. Os princípios ativos das suas folhas são bases 
xantínicas (cafeína e teofilina), proantocianidinas, flavonóides, óleos essenciais, taninos, ácidos fenólicos, vitaminas do complexo B e sais minerais. Em 2015, Cyboran et al. estudaram atividade biológica do suplemento concentrado de chá verde em cápsulas, que continham $300 \mathrm{mg}$ de polifenóis extraídos das folhas e caule do chá verde nas membranas dos eritrócitos. Este extrato além de apresentar atividade antioxidante também inibiu enzimas envolvidas na inflamação como a COX-1, a COX2 e a lipoxigenase, apresentando atividade anti-inflamatória in vitro sem causar efeito deletério em células vermelhas do sangue. O extrato de chá verde modificou as propriedades físicas da membrana, levando ao aumento da resistência, a mudanças da tonicidade, decrescimento da fluidez e aumento da hidratação. Assim estes compostos varrem os radicais livres não permitindo que estes prejudiquem a membrana do eritrócito.

Hrishi et al. (2015) em um estudo clínico randomizado em pacientes com periodontite utilizaram dentifrício com 1,4\% do extrato de chá verde como coadjuvante terapêutico e verificaram melhora estatisticamente significativa em relação ao grupo que não utilizou chá verde nos seguintes parâmetros: índice de placa, profundidade à sondagem, nível clínico de inserção, sangramento à sondagem e atividade da glutationa s-transferase. Assim, o dentifrício com chá verde pode servir como um coadjuvante terapêutico para tratamento da periodontite, sendo de interesse analisar a citotoxicidade de diferentes concentrações do extrato.

Ramadan et al. (2015) estudaram a atividade anti-inflamatória dos extratos aquosos do chá verde versus chá preto em ratos com artrite reumatoide e verificaram que o extrato aquoso de chá verde tem atividade anti-artrítica superior ao extrato aquoso de chá preto. Em 2015, Chen et al. analisaram a ação da 3- galato epigalocatequina (EGCG), um dos principais componentes do chá verde, na atenuação de mastite em ratos induzida por lipopolissacarídeo (LPS). EGCG reduziu as citocinas inflamatórias e inibiu a expressão exarcebada das proteínas quinases ativadas por mitógenos (MAPKs). Marinovic, Morandi e Otton (2015) avaliaram o potencial tanto de uma mistura contendo as quatro principais catequinas presentes no chá verde quanto de cada uma delas separadas como moduladores de parâmetros funcionais de neutrófilos humanos. As quatro catequinas foram EGCG, EGC (galato de epicatequina), ECG (epigalo catequina) e EC (epicatequina). As catequinas sozinhas ou associadas reduziram os parâmetros inflamatórios, pois houve decréscimo da liberação de TNF- $\alpha$, IL-1ß e IL-6, redução da produção de NO e induziu a atividade de enzimas antioxidantes. Os estudos com chá verde são numerosos, mas com extrato glicólico de chá verde ainda são insuficientes, especialmente na Odontologia.

De acordo com Jesus, Oliveira e Oliveira (2015); Oliveira et al., 2014 e Oliveira et al., 2013, existem muitos estudos que utilizam extratos alcoolicos de diversas plantas, entretanto, para uso odontológico externo, o álcool pode agredir as mucosas orais, sendo de interesse analisar extratos livres de álcool, como os extratos glicólicos que possuem propilenoglicol como veículo. Este é muito usado como carreador para 
emulsificantes e como veículo para flavorizantes preferencialmente ao etanol, pois impede a volatilização e fornece um aroma mais estável (ROWE; SHESKEY; WELLER, 2003). Em 2005, Lessmann et al. realizaram um estudo de revisão sobre as propriedades irritantes e sensibilizantes na pele do propilenoglicol. Neste estudo 45.138 pacientes foram avaliados com $20 \%$ de propilenoglicol na pele e somente $0,6 \%$ apresentaram reações irritantes indicando que o propilenoglicol tem baixo potencial de sensibilização da pele. Assim, o propilenoglicol presente nos extratos glicólicos vegetais pode ser empregado em formulações de enxaguatórios bucais e dentifrícios sem risco à saúde.

Os macrófagos são células originadas dos monócitos e estão presentes no tecido conjuntivo ou parênquima de órgãos, podendo viver por meses a anos. Estas células fazem parte do sistema imune e estão envolvidas tanto na inflamação aguda quanto na inflamação crônica.

A resposta inflamatória é a primeira defesa do organismo a um dano tecidual. A inflamação é um processo biológico complexo que envolve alterações vasculares, celulares e uma diversidade de substâncias solúveis, apresentando como sinais clínicos característicos como dor, rubor, calor, edema e prejuízo funcional. A finalidade do processo inflamatório é remover o estímulo lesivo e iniciar a recuperação tecidual local. No processo inflamatório, há aumento da permeabilidade capilar que promove a migração de células como os neutrófilos e monócitos para o tecido lesionado, já no tecido, os monócitos se tornarão macrófagos. Tanto os neutrófilos quantos os macrófagos realizam fagocitose do microrganismo e são ativados para posterior destruição dos patógenos englobados. Macrófagos representam a maioria das células inflamatórias recolhidas das vias aéreas tanto de pessoas saudáveis quanto de pacientes com doença pulmonar obstrutiva crônica (COSTA et al., 2009). Assim, os macrófagos são células importantes na resposta imune que desencadeia um processo inflamatório (TONG et al., 2015).

Diante da variedade de plantas e de extratos, ainda são escassos os estudos sobre a ação citotóxica dos extratos glicólicos da Camellia sinensis, Cynara scolymus e Myracrodruon urundeuva, sendo de grande interesse avaliar suas propriedades a fim de obter fitoterápicos eficientes e com baixa toxicidade, visando aplicabilidade clínica na área odontológica, seja em enxaguatórios, dentifrícios, irrigantes dos canais radiculares e de bolsas periodontais, pomadas, cremes, entre outros. O objetivo deste estudo foi avaliar a atividade citotóxica de diferentes concentrações dos extratos glicólicos de Cynara scolymus (alcachofra), Myracrodruon urundeuva (aroeira-dosertão) e Camellia sinensis (chá verde) em macrófagos de camundongo (RAW 264.7) pelo teste de atividade metabólica MTT.

\section{DESENVOLVIMENTO}

\subsection{Metodologia}


Os experimentos foram realizados no Laboratório de Cultura Celular do Instituto de Ciência e Tecnologia da UNESP.

Os extratos glicólicos de folhas da alcachofra, cascas e folhas da aroeira-dosertão), com concentração de $20 \%(200 \mathrm{mg} / \mathrm{mL})$ em propilenoglicol, foram obtidos pela empresa All Chemistry (São Paulo, SP) e o extrato glicólico das folhas da Camellia sinensis (chá verde), com concentração de $20 \% \quad(200 \mathrm{mg} / \mathrm{mL})$ em propilenoglicol, foi obtido pela empresa Mapric (São Paulo, SP).

A cultura de macrófagos de camundongos (RAW 264.7) foi proveniente do Banco de Células do Rio de Janeiro - Associação Técnico Científica Paul Ehrlich (APABCAM - RJ).

Os testes de citotoxicidade de cada extrato foram avaliados em culturas de macrófagos de camundongo (RAW 264.7) após exposição a 11 diluições seriadas de cada extrato, em dois períodos de contato: 5 min e 24 horas. A cultura de macrófagos foi cultivada em meio de Eagle modificado por Dulbecco (DMEM - LGC Biotecnologia, Cotia, Brasil), suplementado com 10\% de soro fetal bovino (SFB) (Invitrogen, Nova York, EUA) e mantidas em frascos de cultivo celular (TPP, Suíça), incubadas em estufa à temperatura de $37^{\circ} \mathrm{C}$, com umidade atmosférica, com $5 \%$ de $\mathrm{CO}_{2}$. As células viáveis foram contadas pelo Countess Cell e, em microplacas de 96 poços foram adicionados $200 \mu \mathrm{L}$ de meio (DMEM + 10\% SFB) contendo $2 \times 10^{4}$ células viáveis. Estas placas foram incubadas $\left(37^{\circ} \mathrm{C}\right.$, com $5 \%$ de $\left.\mathrm{CO}_{2}\right)$ por $24 \mathrm{~h}$ para aderência celular nos poços da microplaca. Em seguida, o sobrenadante foi descartado e foram acrescentados 200 $\mu \mathrm{L} /$ poço de cada extrato em 11 concentrações diferentes: $200 \mathrm{mg} / \mathrm{mL}, 100 \mathrm{mg} / \mathrm{mL}, 50$ $\mathrm{mg} / \mathrm{mL}, 25 \mathrm{mg} / \mathrm{mL}, 12,5 \mathrm{mg} / \mathrm{mL}, 6,25 \mathrm{mg} / \mathrm{mL}, 3,13 \mathrm{mg} / \mathrm{mL}, 1,56 \mathrm{mg} / \mathrm{mL}, 0,78 \mathrm{mg} / \mathrm{mL}$, $0,39 \mathrm{mg} / \mathrm{mL}$ e $0,20 \mathrm{mg} / \mathrm{mL}$. Para cada concentração do extrato foram realizadas 8 repetições $(n=8)$. Os períodos de exposição a cada extrato foram de 5 min e 24 horas, totalizando 528 amostras. Foram utilizados poços-controles, contendo apenas células com meio de cultura. Após o tempo de exposição, o sobrenadante de cada poço foi descartado e os poços lavados com PBS. Em seguida, para verificação da viabilidade da cultura, foram adicionados $100 \mu \mathrm{L} /$ poço da solução de MTT [3(4,5-dimetiltiazol-2yl)2,5-difeniltetrazólio- Sigma Aldrich, na concentração de $0,5 \mathrm{mg} / \mathrm{mL}$. As placas foram incubadas novamente $\left(37^{\circ} \mathrm{C} / 5 \%\right.$ de $\left.\mathrm{CO}_{2}\right)$ por período de $1 \mathrm{~h}$, abrigadas da luz. Posteriormente, esta solução foi descartada e foram adicionados $100 \mu \mathrm{L} /$ poço de dimetilsulfóxido (DMSO - Sigma). Após incubação de 10 min e agitação em shaker por igual período, a absorbância foi lida a $570 \mathrm{~nm}$. As densidades ópticas (DO) obtidas foram convertidas em percentual de viabilidade celular, comparando-as com o grupo controle. A metodologia foi baseada nos artigos de Jesus et al, 2015; Oliveira et al., 2014 e Oliveira et al., 2013. Os dados foram analisados estatisticamente pelo método ANOVA complementado pelo Teste de Tukey, com nível de significância de 5\% $(p \leq 0.05)$. 


\subsection{Resultados}

Com relação ao tempo de contato de $5 \mathrm{~min}$, pode-se verificar que no caso do chá verde (Camellia sinensis) todas as 11 concentrações analisadas apresentaram valores de viabilidade celular acima de 100\% (Figura 1). O extrato de aroeira-do-sertão (M. urundeuva) apresentou viabilidade celular superior a $69 \%$ na concentração de 200 $\mathrm{mg} / \mathrm{mL}(69,85 \pm 14,37 \%)$, seguida da concentração de $6,25 \mathrm{mg} / \mathrm{mL}$ que apresentou viabilidade celular de $86,74 \pm 8,91 \%$. As demais concentrações apresentaram viabilidade celular superior a $100 \%$ (Figura 2). No caso do extrato de alcachofra ( $C$. scolymus), pode-se verificar significativa redução da viabilidade celular na concentração de $200 \mathrm{mg} / \mathrm{mL}$, a qual apresentou apenas 17,97 $\pm 4,96 \%$ de células viáveis. Na concentração de $1,56 \mathrm{mg} / \mathrm{mL}$ a viabilidade foi de $52,91 \pm 19,74 \%$ e na concentração de $25 \mathrm{mg} / \mathrm{mL}$ a viabilidade celular foi de $52,31 \pm 7,48 \%$. No caso do extrato de alcachofra, os valores de viabilidade celular mais próximos do grupo controle, foram obtidos com as concentrações de $0,39 \mathrm{mg} / \mathrm{mL}(71,15 \pm 30,78 \%)$ e 0,20 $\mathrm{mg} / \mathrm{mL}(77,49 \pm 24,29 \%$ ) (Figura 3).

Com relação ao tempo de contato de 24 horas, o extrato de chá verde (Camellia sinensis) apresentou significativa redução da viabilidade celular nas concentrações de $50 \mathrm{mg} / \mathrm{mL}, 100 \mathrm{mg} / \mathrm{mL}$ e $200 \mathrm{mg} / \mathrm{mL}$, as quais apresentaram viabilidade celular de: $9,98 \pm 1,74 \%, 10,53 \pm 1,37 \%, 14,98 \pm 3,11 \%$, respectivamente. Já na concentração de $25 \mathrm{mg} / \mathrm{mL}$ a viabilidade foi de $81,87 \pm 14$ e nas demais concentrações foi próximo de $100 \%$ (Figura 4). O extrato de aroeira-do-sertão ( $M$. urundeuva) apresentou viabilidade celular superior a $50 \%$ em todas as concentrações analisadas, sendo que as concentrações maiores do extrato de $50 \mathrm{mg} / \mathrm{mL}$ a $200 \mathrm{mg} / \mathrm{mL}$ apresentaram viabilidade celular entre $56,74 \pm 8,89 \%$ e $57,41 \pm 9,95 \%$. A concentração de $25 \mathrm{mg} / \mathrm{mL}$ apresentou viabilidade celular de $71,80 \pm 13,05 \%$ e as demais concentrações apresentaram valores superiores a $100 \%$ (Figura 5). O extrato de alcachofra ( $C$. scolymus) apresentou significativa redução da viabilidade celular nas concentrações de $12,5 \mathrm{mg} / \mathrm{mL}$ a $200 \mathrm{mg} / \mathrm{mL}$, com viabilidade celular abaixo de $50 \%$, sendo: $20,05 \pm$ 2,55\% (200 mg/mL), 7,37 $\pm 0.94 \%(100 \mathrm{mg} / \mathrm{mL}), 6,08 \pm 0,58 \%(50 \mathrm{mg} / \mathrm{mL}), 26,37 \pm$ $4,34 \%(25 \mathrm{mg} / \mathrm{mL})$ e $27,27 \pm 4,16 \%(25 \mathrm{mg} / \mathrm{mL})$. As demais concentrações apresentaram valores próximos a 100\% sendo semelhantes ao grupo controle (Figura $6)$. 
Figura 1 - Teste de citotoxicidade do extrato de chá verde no tempo de exposição de 5 minutos.

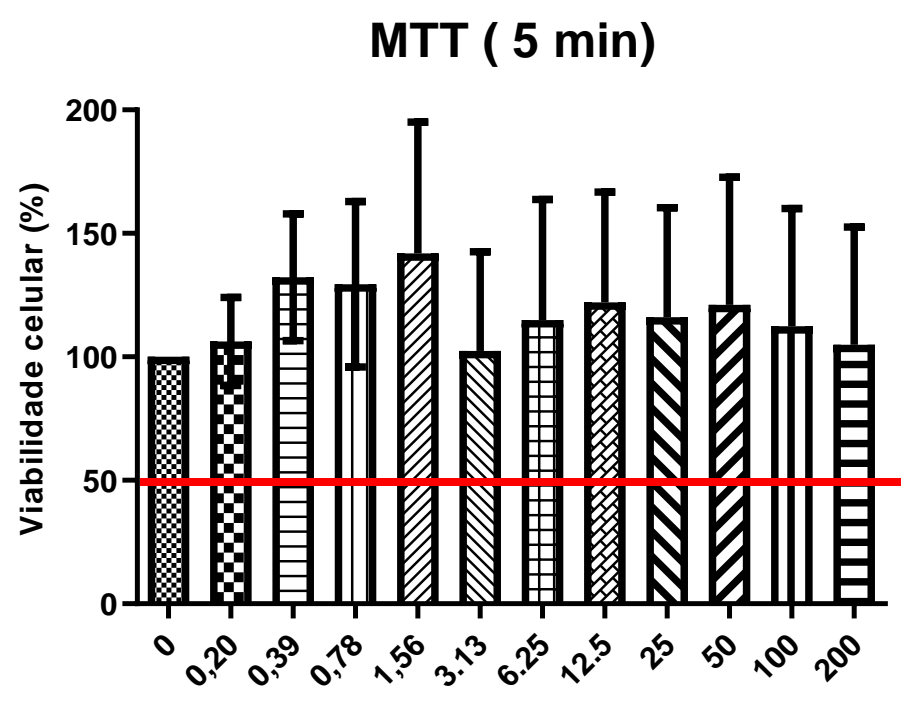

Concentração do extrato de chá verde $(\mathrm{mg} / \mathrm{mL})$

Fonte: Os autores.

Figura 1 - Viabilidade celular (\%) apresentada por macrófagos não tratados $(0 \mathrm{mg} / \mathrm{mL})$ e tratados por 5 min com extrato de chá verde nas concentrações $(200 \mathrm{mg} / \mathrm{mL}, 100$ $\mathrm{mg} / \mathrm{mL}, 50 \mathrm{mg} / \mathrm{mL}, 25 \mathrm{mg} / \mathrm{mL}, 12,5 \mathrm{mg} / \mathrm{mL}, 6,25 \mathrm{mg} / \mathrm{mL}, 3,13 \mathrm{mg} / \mathrm{mL}, 1,56 \mathrm{mg} / \mathrm{mL}$, $0,78 \mathrm{mg} / \mathrm{mL}, 0,39 \mathrm{mg} / \mathrm{mL}$ e $0,20 \mathrm{mg} / \mathrm{mL})(\mathrm{n}=8)$. ANOVA e Testes de Tukey com nível de significância de $5 \%$.

Figura 2 - Teste de citotoxicidade do extrato de aroeira-do-sertão no tempo de exposição de 5 minutos.

MTT ( 5 min )

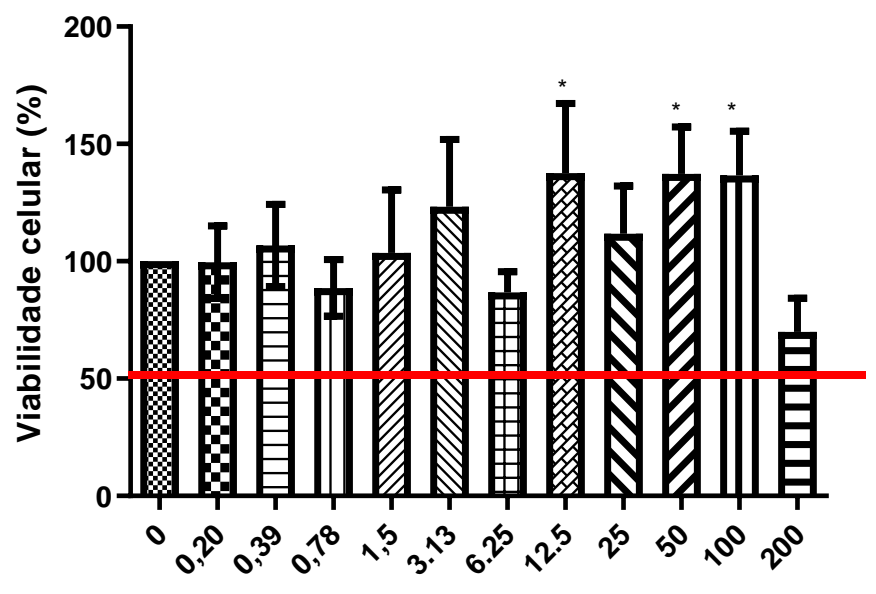

Concentração do extrato de aroeira-do-sertão $(\mathrm{mg} / \mathrm{mL})$

Fonte: Os autores. 
Figura 2 - Viabilidade celular (\%) apresentada por macrófagos não tratados $(0 \mathrm{mg} / \mathrm{mL})$ e tratados por 5 min com extrato de aroeira-do-sertão nas concentrações (200 $\mathrm{mg} / \mathrm{mL}, 100 \mathrm{mg} / \mathrm{mL}, 50 \mathrm{mg} / \mathrm{mL}, 25 \mathrm{mg} / \mathrm{mL}, 12,5 \mathrm{mg} / \mathrm{mL}, 6,25 \mathrm{mg} / \mathrm{mL}, 3,13 \mathrm{mg} / \mathrm{mL}, 1,56$ $\mathrm{mg} / \mathrm{mL}, 0,78 \mathrm{mg} / \mathrm{mL}, 0,39 \mathrm{mg} / \mathrm{mL}$ e $0,20 \mathrm{mg} / \mathrm{mL})(\mathrm{n}=8)$. ANOVA e Testes de Tukey com nível de significância de 5\%.

Figura 3 - Teste de citotoxicidade do extrato de alcachofra no tempo de exposição de 5 minutos.

\section{MTT ( 5 min )}

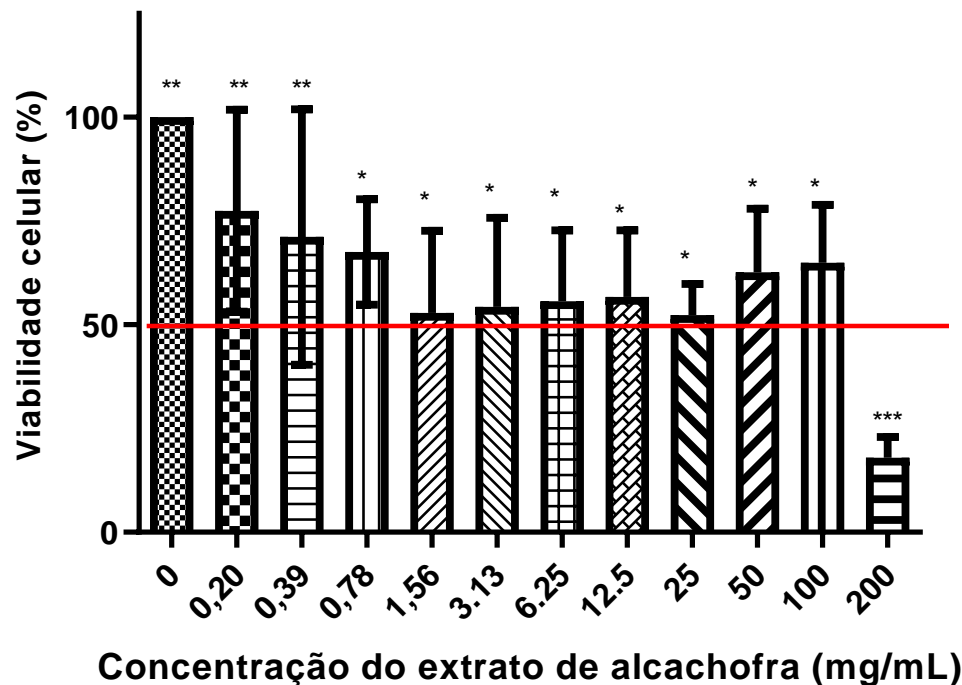

Fonte: Os autores.

Figura 3 - Viabilidade celular (\%) apresentada por macrófagos não tratados $(0 \mathrm{mg} / \mathrm{mL})$ e tratados por 5 minutos com extrato de alcachofra nas concentrações (200 $\mathrm{mg} / \mathrm{mL}, 100 \mathrm{mg} / \mathrm{mL}, 50 \mathrm{mg} / \mathrm{mL}, 25 \mathrm{mg} / \mathrm{mL}, 12,5 \mathrm{mg} / \mathrm{mL}, 6,25 \mathrm{mg} / \mathrm{mL}, 3,13 \mathrm{mg} / \mathrm{mL}, 1,56$ $\mathrm{mg} / \mathrm{mL}, 0,78 \mathrm{mg} / \mathrm{mL}, 0,39 \mathrm{mg} / \mathrm{mL}$ e $0,20 \mathrm{mg} / \mathrm{mL})(\mathrm{n}=8)$. ANOVA e Testes de Tukey com nível de significância de $5 \%$. 
Figura 4 - Teste de citotoxicidade do extrato de chá-verde no tempo de exposição de 24 horas.

\section{MTT ( 24 horas)}

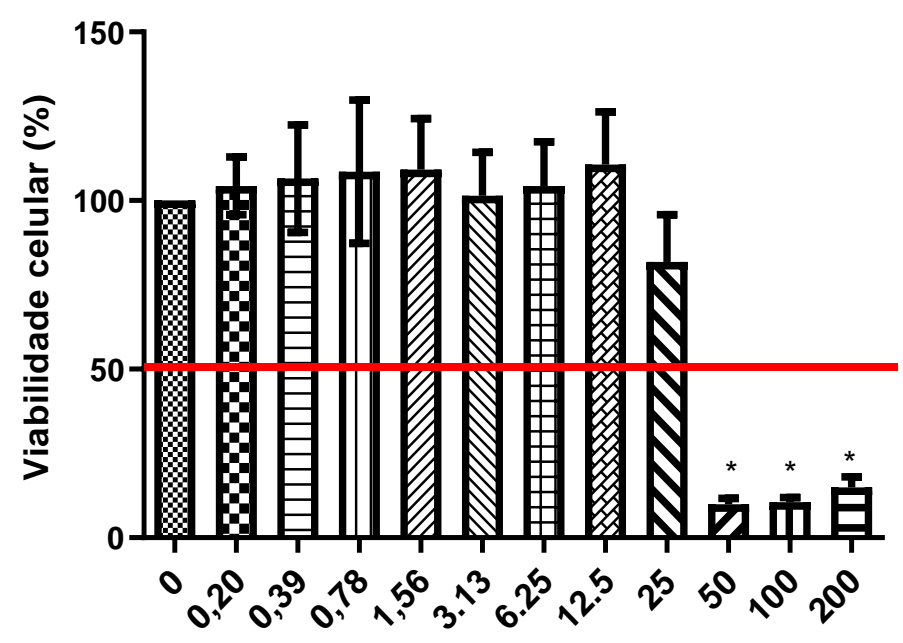

Concentração de extrato de chá verde $(\mathrm{mg} / \mathrm{mL})$

Fonte: Os autores.

Figura 4 - Viabilidade celular (\%) apresentada por macrófagos não tratados $(0 \mathrm{mg} / \mathrm{mL})$ e tratados por $24 \mathrm{~h}$ com extrato de chá verde nas concentrações $(200 \mathrm{mg} / \mathrm{mL}, 100$ $\mathrm{mg} / \mathrm{mL}, 50 \mathrm{mg} / \mathrm{mL}, 25 \mathrm{mg} / \mathrm{mL}, 12,5 \mathrm{mg} / \mathrm{mL}, 6,25 \mathrm{mg} / \mathrm{mL}, 3,13 \mathrm{mg} / \mathrm{mL}, 1,56 \mathrm{mg} / \mathrm{mL}$,

$0,78 \mathrm{mg} / \mathrm{mL}, 0,39 \mathrm{mg} / \mathrm{mL}$ e 0,20 mg/mL) (n=8). ANOVA e Testes de Tukey com nível de significância de $5 \%$.

Figura 5 - Teste de citotoxicidade do extrato de aroeira-do-sertão no tempo de exposição de 24 horas.

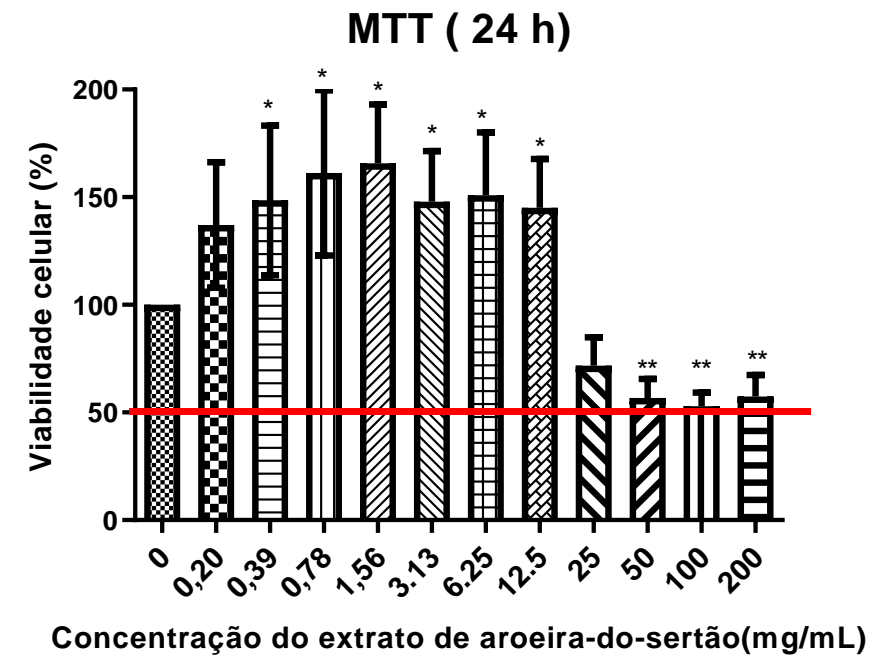

Fonte: Os autores. 
Figura 5 - Viabilidade celular (\%) apresentada por macrófagos não tratados $(0 \mathrm{mg} / \mathrm{mL})$ e tratados por $24 \mathrm{~h}$ com extrato de aroeira-do-sertão nas concentrações (200

$\mathrm{mg} / \mathrm{mL}, 100 \mathrm{mg} / \mathrm{mL}, 50 \mathrm{mg} / \mathrm{mL}, 25 \mathrm{mg} / \mathrm{mL}, 12,5 \mathrm{mg} / \mathrm{mL}, 6,25 \mathrm{mg} / \mathrm{mL}, 3,13 \mathrm{mg} / \mathrm{mL}, 1,56$ $\mathrm{mg} / \mathrm{mL}, 0,78 \mathrm{mg} / \mathrm{mL}, 0,39 \mathrm{mg} / \mathrm{mL}$ e $0,20 \mathrm{mg} / \mathrm{mL})(\mathrm{n}=8)$. ANOVA e Testes de Tukey com nível de significância de $5 \%$.

Figura 6 - Teste de citotoxicidade do extrato de alcachofra no tempo de exposição de 24 horas.

\section{MTT ( $24 \mathrm{~h}$ )}

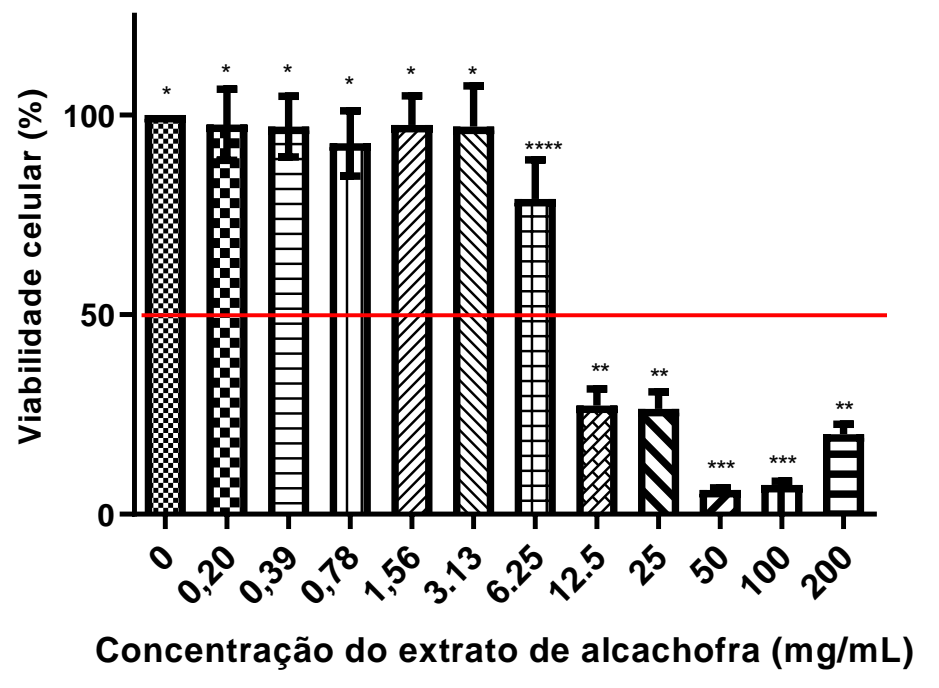

Fonte: Os autores.

Figura 6 - Viabilidade celular (\%) apresentada por macrófagos não tratados $(0 \mathrm{mg} / \mathrm{mL})$ e tratados por $24 \mathrm{~h}$ com extrato de alcachofra nas concentrações $(200 \mathrm{mg} / \mathrm{mL}, 100$ $\mathrm{mg} / \mathrm{mL}, 50 \mathrm{mg} / \mathrm{mL}, 25 \mathrm{mg} / \mathrm{mL}, 12,5 \mathrm{mg} / \mathrm{mL}, 6,25 \mathrm{mg} / \mathrm{mL}, 3,13 \mathrm{mg} / \mathrm{mL}, 1,56 \mathrm{mg} / \mathrm{mL}$, $0,78 \mathrm{mg} / \mathrm{mL}, 0,39 \mathrm{mg} / \mathrm{mL}$ e 0,20 mg/mL) (n=8). ANOVA e Testes de Tukey com nível de significância de $5 \%$.

\subsection{Discussão}

Durante a avaliação da citotoxicidade no tempo de exposição de 5 minutos, as concentrações dos três extratos obtiveram valores de viabilidade celular maiores que $50 \%$ indicando que o tempo de exposição de 5 minutos não foi citotóxico, exceto para a concentração de alcachofra $200 \mathrm{mg} / \mathrm{mL}$. Os valores de viabilidade celular mais próximos do controle independente da concentração foram respectivamente do chá verde, aroeira-do-sertão e alcachofra. Jesus et al. em 2015 realizou o MTT no tempo de exposição de $5 \mathrm{~min}$ do extrato glicólico de abacateiro (Persea americana) e observou a partir de concentrações de $25 \mathrm{mg} / \mathrm{mL}$ para baixo, que a viabilidade celular ficou maior que $75 \%$, e que no estudo atual, a alcachofra, no mesmo tempo de exposição e concentrações, sua viabilidade celular ficou em torno de $55 \%$ 
apresentando menor viabilidade celular que o abacateiro

No tempo de exposição de 24 horas, observou-se valores citotóxicos em 3 concentrações do chá verde $(50,100$ e $200 \mathrm{mg} / \mathrm{mL})$ e em 4 concentrações da alcachofra $(12,5 ; 50 ; 100$ e $200 \mathrm{mg} / \mathrm{mL})$, pois nestas concentrações houve uma redução da viabilidade celular para menos de $50 \%$.

Já o extrato de aroeira-do-sertão apresentou viabilidade celular superior a $50 \%$ em todas as concentrações analisadas. Ao comparar com estudos da aroeira-da praia (Schinus terebinthifolius) que pertence a mesma família Anacardicaeae há resultados que indicam sua ação cicatrizante. Ribas et al. (2006), que verificou que o uso tópico de extrato das folhas de aroeira (Schinus terebinthifolius) promoveu maior proliferação vascular e fibroblástica em relação ao grupo controle. Estevão et al. (2013; 2015) verificaram importante papel do extrato de aroeira (Schinus terebinthifolius) em acelerar o processo de cicatrização em feridas da pele de ratos, com aumento do número de fibroblastos, fibras colágenas e mastócitos. Assim, pode-se verificar que o extrato de aroeira-do-sertão possui grande potencial para uso odontológico, sendo importante ampliar as pesquisas visando seu uso como, por exemplo, enxaguatório bucal em casos de doença periodontal.

O chá verde promoveu aumento da viabilidade celular em todas concentrações no tempo de contato de $5 \mathrm{~min}$. No tempo de exposição de 24 horas, da concentração de $0,20 \mathrm{mg} / \mathrm{mL}$ a $12,5 \mathrm{mg} / \mathrm{mL}$ a viabilidade celular foi maior que $100 \%$. A estimulação da proliferação dos macrófagos pode estar relacionada a atividade antioxidante do chá verde, já observada por Cyboran et al. (2015) que verificaram a atividade antioxidante em extratos secos das folhas e caule do chá verde que na concentração de 5,93 $\pm 0,18$ $\mu \mathrm{g} / \mathrm{mL}$ apresentou $50 \%$ de inibição da peroxidação.

Em 2014, de Oliveira et al. analisaram a citotoxicidade do extrato glicólico de Arctium lappa L. em macrófagos (RAW 264.7), pelo tempo de contato de 5 min, e verificaram nas concentrações de 250, 125 e $62.5 \mathrm{mg} / \mathrm{mL}$ do extrato valores de viabilidade celular semelhantes ao grupo controle, no estudo com aroeira-do-sertão e chá verde em concentrações de 200, 100 e $50 \mathrm{mg} / \mathrm{mL}$ os valores ficaram acima de grupo controle e para alcachofra os valores na concentração de 100 e $50 \mathrm{mg} / \mathrm{mL}$ ficaram em torno de $60 \%$. Assim, a alcachofra apresenta menor viabilidade celular comparada com a bardana. Em 2013, Oliveira et al. analisaram a citotoxicidade pelo teste de MTT em macrófagos (RAW 264.7), tempo de exposição de $5 \mathrm{~min}$, dos extratos glicólicos das seguintes espécies vegetais: Equisetum arvense L., Glycyrrhiza glabra L., Punica granatum L. and Stryphnodendron barbatimam Mart. e verificaram na concentração de $50 \mathrm{mg} / \mathrm{mL}$ de cada um dos extratos as respectivas viabilidades celulares: $48 \pm 5.29 \%, 52 \pm 2.96 \%, 76 \pm 3.10 \%$ e $86 \pm 4.05 \%$. A viabilidade celular foi menor que $50 \%$ apenas no grupo tratado com Equisetum arvense $\mathrm{L}$. No presente estudo na mesma concentração de $50 \mathrm{mg} / \mathrm{mL}$ para cada um dos extratos de alcachofra, chá verde e aroeira-do-sertão a viabilidade foi respectivamente em torno 
de $63 \%, 122 \%$ e $137 \%$, assim os resultados sugerem que o chá verde e aroeira-dosertão estimulam a proliferação dos macrófagos e nesta concentração os três extratos não apresentam citotoxicidade.

Com relação à citotoxicidade no tempo de exposição de 24 horas comparando os valores da viabilidade celular dos três extratos na concentração de $12,5 \mathrm{mg} / \mathrm{mL}$, o extrato de aroeira-do-sertão apresentou 145,08 $\pm 22,72 \%$, o extrato de chá verde $110,63 \pm 15,74 \%$ e o extrato de alcachofra $27,27 \pm 4,16 \%$. Assim o extrato de alcachofra foi o que apresentou maior citotoxicidade, com viabilidade celular bem abaixo de $50 \%$.

\section{CONCLUSÃO}

Os estudos de citotoxicidade de produtos naturais como os extratos glicólicos das plantas são importantes para a aplicação clínica desses componentes em diversas áreas da saúde, incluindo a odontologia, com seu uso em formulações de enxaguatórios bucais, dentifrícios e irrigantes intracanais. De acordo com os resultados deste estudo, pode-se concluir que a citotoxicidade dos extratos é dose e tempo dependentes, de modo que o extrato de chá verde foi o menos citotóxico nos tempos de contato de 5 minutos e $24 \mathrm{~h}$, seguido pelo extrato de aroeira-do-sertão. $\mathrm{O}$ extrato de alcachofra foi o que apresentou maior citotoxicidade. Assim, sugere-se que os estudos com extratos glicólicos de chá verde e aroeira-do-sertão sejam ampliados a fim de analisar seu potencial anti-inflamatório e antimicrobiano, para direcionar seu uso terapêutico nas concentrações não citotóxicas.

\section{REFERÊNCIAS}

CARLINI, E. A.; DUARTE-ALMEIDA, J. M.; TABACH, R. Assessment of the toxicity of the Brazilian pepper trees Schinus terebinthifolius Raddi (Aroeira-da-praia) and Myracrodruon urundeuva Allemão (Aroeira-do-sertão). Phytother Res. United States, v. 5, n. 27, p. 692-8, 2013. Disponível em : < https://doi.org/10.1002/ptr.4767 >. Acesso em: 04 fev. 2019.

CARVALHO, N. B. V. et al. Ethnopharmacological study of plants sold for therapeutic purposes in public markets in Northeast Brazil. J Ethnopharmacol. United States, v. 172, p. 265-72, 2015.

Disponível em : <https://doi.org/10.1016/j.jep.2015.06.022 >. Acesso em: 04 fev. 2019.

CHEN J. et al. Epigallocatechin-3-gallate attenuates lipopolysaccharide-induced mastitis in rats via suppressing MAPK mediated inflammatory responses and oxidative stress. Int Immunopharmacol. United States, May. v. 1, n. 26, p. 147-52, 2015. Disponível em : <https://doi.org/10.1016/j.intimp.2015.03.025>. Acesso em: 04 fev. 2019.

COSTA, C.H. et al. Células inflamatórias e seus mediadores na patogênese da DPOC. Rev. Assoc. Med. Bras. Brasil, v. 3, n. 55, p. 347-54, 2009. Disponível em : <http://www.scielo.br/pdf/ramb/v55n3/v55n3a31.pdf>. Acesso em: 31 mar. 2019. 
CYBORAN, S. et al. Concentrated green tea supplement: biological activity and molecular mechanisms. Life Sci. New England, April., v. 126, p. 100-109, 2015. Disponível em : <https://doi.org/10.1016/j.Ifs.2014.12.025>. Acesso em: 04 fev. 2019.

ESTEVÃO, L.R. et al. Mast cell concentration and skin wound contraction in rats treated with Brazilian pepper essential oil (Schinus terebinthifolius Raddi). Acta Cir Bras., v. 30, n. 4, p. 289-95, 2015. Disponível em : < http://dx.doi.org/10.1590/S0102865020150040000008 >. Acesso em: 04 fev. 2019.

ESTEVÃO, L. R. et al. Effects of aroeira-do-praia (Schinus terebinthifolius Raddi) oil on cutaneous wound healing in rats. Acta Cir Bras., v. 3, n. 28, p. 202-9, 2013. Disponível em: <http://dx.doi.org/10.1590/S0102-86502013000300008 >. Acesso em: 04 fev. 2019.

FREIRES, I. A. et al. A Randomized Clinical Trial of Schinus terebinthifolius Mouthwash to Treat Biofilm-Induced Gingivitis. Evid Based Complement Alternat Med. Cairo, v. 2013, Article ID 873907, 8 pages, 2013.

Disponível em: <http://dx.doi.org/10.1155/2013/873907>. Acesso em: 04 fev. 2019.

HRISHI, T. et al. Effect of adjunctive use of green tea dentifrice in periodontitis patients - A Randomized Controlled Pilot Study. Int J Dent Hyg. Sweden, ago., v. 14, n. 3, p. 178-83, 2015. Disponível em:

<https://onlinelibrary.wiley.com/doi/full/10.1111/idh.12131>. Acesso em: 04 fev. 2019.

JESUS, D.; OLIVEIRA, J. R.; OLIVEIRA F. E. et al. "Persea americana Glycolic Extract: In Vitro Study of Antimicrobial Activity against Candida albicans Biofilm and Cytotoxicity Evaluation". The Scientific World Journal,Cairo, v. 2015, Article ID 531972, p. 1-5, 2015. Disponível em: <https://doi.org/10.1155/2015/531972>. Acesso em: 04 fev. 2019.

LESSMANN, H. et al. Skin-sensitizing and irritant properties of propyleneglycol. Contact Dermatitis. Singapore. v. 2005, n. 53, p. 247-259, 2005. Disponível em: <https://doi.org/10.1111/j.0105-1873.2005.00693.x>. Acesso em: 04 fev. 2019.

MARINOVIC, M. P.; MORANDI A. C.; OTTON, R. Green tea catechins alone or in combination alter functional parameters of human neutrophils via suppressing the activation of TLR-4/NFk $\beta$ p 65 signal pathway. Toxicology in Vitro. Netherlands, $v 29$, p. 1766-1778, 2015. Disponível em: <https://doi.org/10.1016/j.tiv.2015.07.014>. Acesso em: 04 fev. 2019.

OLIVEIRA, J. R. et al. Cytotoxicity of Brazilian plant extracts against oral microorganisms of interest to dentistry. BMC Complement Altern Med. UK, v. 13, n. 208, p. 1-7, 2013. Disponível em: <https://doi: 10.1186/1472-6882-13-208 >. Acesso em: 04 fev. 2019.

OLIVEIRA, J. R. et al. Control of microorganisms of oral health interest with Arctium lappa L. (burdock) extract non-cytotoxic to cell culture of macrophages (RAW 264.7). Arch Oral Biol. UK, v. 59, n. 8, p. 808-14, 2014. Disponível em: <https://doi: 10.1016/j.archoralbio.2014.05.013>. Acesso em: 04 fev. 2019.

RAMADAN, G. et al. Anti-inflammatory activity of green versus black tea aqueous extract in a rat model of human rheumatoid arthritis. Int $\mathbf{J}$ Rheum Dis. Austrália, May., v. 20, p. 203-213, 2015. Disponível em: < http://doi: 10.1111/1756-185X.12666>.

Acesso em: 04 fev. 2019. 
RIBAS, M.O. et al. Efect of the Schinus terebinthifolius Raddi in the process of tissular repair in ulcers induced in mucosa oral of the rat. Journal of Dental Sciences, n. 21, p. 245-252, 2006. Disponível em: <http://dx.doi.org/10.1155/2013/873907>. Acesso em: 04 fev. 2019.

ROWE, R. C.; SHESKEY, P. J.; WELLER, P. J. Handbook of pharmaceutical excipients. 4. ed. Londres: Pharmaceutical Press, 2003.

SARAIVA, M. E. et al. Plant species as a therapeutic resource in areas of the savanna in the state of Pernambuco, Northeast Brazil. J Ethnopharmacol. South Africa,Aug. v. 171, p. 141-153, 2015. Disponível em: < https://doi.org/10.1016/j.jep.2015.05.034 >. Acesso em: 04 fev. 2019.

TANAKA, Y.T. et al. Cynaropicrin from Cynara scolymus L. suppresses photoaging of skin by inhibiting the transcription activity of nuclear factor-kappa B. Bioorg Med Chem Lett. USA, Jan. v. 23, n. 2, p. 518-23, 2013. Disponível em:

<https://doi.org/10.1016/j.bmcl.2012.11.034>. Acesso em: 04 fev. 2019.

TONG, $H$. et al. Macrophage activation induced by the polysaccharides isolated from the roots of Sanguisorba officinalis. Pharm Biol., USA, Out. v. 10, n. 53, p.1511-5, 2015.Disponível em: <https://doi.org/10.3109/13880209.2014.991834>. Acesso em: 03 mar.2016.

ZAPOLSKA-DOWNAR, D. et al. Protective properties of artichoke (Cynara scolymus) against oxidative stress induced in cultured endothelial cells and monocytes. Life Sci. New England., Nov., v. 71, n. 24, p. 2897-2908, 2002. Disponível em:

<https://doi.org/10.1016/S0024-3205(02)02136-7>. Acesso em: 04 fev. 2019. 